\title{
Precision Medicine for Idiopathic Hypersomnia
}

Isabelle Arnulf,* MD, PhD, Smaranda Leu-Semenescu, MD, and Pauline Dodet, MD

*Corresponding author: National Reference Center for Rare Hypersomnias, Pitie-Salpetriere University Hospital and Sorbonne University, 47-85 Boulevard de 1'Hôpital, 75013 Paris, France

\section{E-mail address for Dr. Arnulf: isabelle.arnulf@aphp.fr}

\section{Synopsis}

Idiopathic hypersomnia (IH) is characterized by excessive daytime sleepiness despite normal or prolonged sleep. IH is distinguished from narcolepsy by the female predominance, severe morning inertia, continuous drowsiness (rather than sleep attacks), and unrefreshing naps, as well as the absence of cataplexy, sleep onset in REM periods, and hypocretin deficiency. In IH, the MSLT demonstrates low sensitivity, specificity and reproducibility, compared prolonged sleep monitoring. In some IH cases, an endogenous hypnotic peptide stimulating GABA receptors during wakefulness is suspected, which are improved by anti-GABA (e.g., clarithromycine) drugs. The benefit of modafinil, sodium oxybate, mazindol and pitolisant were found in mostly retrospective studies.

Disclosure statement: The authors declare that they have no conflicts of interest related to this chapter.

\section{Key points:}

- Idiopathic hypersomnia is characterized by excessive daytime sleepiness despite normal or prolonged sleep

- Drowsiness, starting since morning awakening, and being continuous over daytime, is more common in IH than the sleep attacks observed in narcolepsy

- New studies insist on the lack of sensitivity, specificity and reproducibility of multiple sleep latency tests, and the interest of measuring sleep excess on prolonged protocols

- Cerebrospinal fluid (CSF) analysis suggest that some patients with resistant central hypersomnia may produce during wakefulness an endogenous peptide binding GABA-A receptors. 
- Functional brain imaging support this concept, with low activity of the medial prefrontal cortex during wakefulness in $\mathrm{IH}$ patients

- Retrospective and rare placebo-controlled studies illustrate the respective benefit of modafinil, sodium oxybate, pitolisant, mazindol, flumazenil and clarithromycin in IH treatment.

Key words: hypersomnia, long sleep time, drowsiness, GABA, modafinil, sodium oxybate 


\section{Introduction}

Idiopathic hypersomnia $(\mathrm{IH})$ is a rare sleep disorder characterized by excessive daytime sleepiness (without sleep onset in REM periods, SOREMPs), despite normal, undisturbed sleep, of normal or prolonged duration. However, this simple definition broadly covers various clinical profiles of patients, which may be captured by different methods of sleep monitoring, and which illustrate the interest of precision medicine in this disorder. Furthermore, IH definitions have suffered from their contrast with narcolepsy type 1, in which several pathognomonic features, including cataplexy, sleep onset in REM periods (SOREMP), and later cerebrospinal fluid (CSF) hypocretin-1 deficiency define a more homogeneous disorder. To date, there is no definitive biological markers and causes for IH. In addition, the clinical phenotypes and sleep abnormalities (e.g., multiple sleep latency test, MSLT vs long term monitoring) are heterogeneous. In the last decade, several cohorts have highlighted the lack of sensitivity and long-term reproducibility of the MSLT in patients with IH (and with narcolepsy type 2) and have tried to develop other methods of sleep monitoring to assess patient symptoms more objectively and to define normative values. A major step in identifying the etiology of central hypersomnolence disorders (apart from hypocretin-1 deficiency), was reached when the Atlanta (Georgia, USA) group found indirect evidence that an endogenous hypnotic neurotransmitter when secreted, stimulates GABA-A receptors in some IH patients (mostly those multi-resistant to stimulants). In addition, functional brain imaging suggests that the medial prefrontal cortex of IH patients is "asleep" when they would otherwise be characterized as awake. Subsequently, there have been formal, placebo controlled evaluations of modafinil and clarithromycin in $\mathrm{IH}$, and retrospective series showing the benefit of sodium oxybate, mazindol, flumazenil and the new pro-histamine stimulant, pitolisant, in IH.

In many textbooks, IH is often described as "what it is not" (e.g., it is not a narcolepsy, a mild chronic sleep insufficiency, especially in long sleepers, an upper airway resistance syndrome, a mood disorder with sleepiness, a post-traumatic hypersomnia, a NREM parasomnia with daytime sleepiness). Since IH is a diagnosis of exclusion, these conditions should first be ruled out. The association of IH symptoms with chronic fatigue syndrome/myalgia, attention deficit hyperactivity disorder and mood disorders raises the potential for overlap with these disorders and the need for more objective measures. In this article, we will discuss IH alone and presume that the other hypersomnia disorders have been ruled out by experienced sleep specialists. 


\section{History}

Abnormal hypersomnia has been recognized with various terms (idiopathic narcolepsy, NREM narcolepsy, functional, mixed, or harmonious hypersomnia) since the $19^{\text {th }}$ century. Bedrich Roth (Prague, Czech Republic) is considered to be the father of the disorder, having described, since the 1940s, a large series of patients suffering from non-narcoleptic daytime sleepiness with sleep drunkenness. ${ }^{1}$ Although, some patients in this first series likely suffered from sleep apnea, many of them had clinical features suggestive of IH with long sleep time. In the International Classification of Sleep Disorders (ICSD), the disorder was coined as "idiopathic central nervous system hypersomnolence" in 1979. The condition, named "idiopathic hypersomnia" in $1990{ }^{2}$ was split between IH with versus without long sleep time in $2005,{ }^{3}$ and later merged together in $2013 .{ }^{4}$ There has been more recent debate to split the condition again, to merge narcolepsy type 2 and IH without long sleep time together and to isolate IH with long sleep time as a separate entity. This "coming and going" movement illustrates the difficulty to define clinical phenotypic clusters in IH. Indeed, studies on IH remain scarce, especially if one compares to the number of publications on narcolepsy, a rare disorder, and on Kleine-Levin syndrome, a much rarer syndrome (but has some pathognomic clinical features).

\section{Epidemiology of IH}

The exact prevalence of IH is unknown, but it is slightly less frequent in expert centers than narcolepsy, suggesting a prevalence of 1 to 2 affected persons for 10,000 inhabitants. The disorder mostly starts during adolescence and early adulthood (Table 1). Several series of IH patients in expert sleep centers indicate that IH affects women (75\%) more than men and more frequently Caucasian persons (Table 1). The familial appearance of this disorder is observed more frequently than in narcolepsy, but no formal study of familial aggregation have been published to date. The IH rarity can be compared to daytime sleepiness associated with long sleep in epidemiological studies. In the general population, $1.6 \%$ of adults reported sleeping more than $9 \mathrm{~h}$ per $24 \mathrm{~h}$ with concomitant distress or daytime impairment. ${ }^{5}$ This sample contained more women, more young (18-24 y old) and older ( $>65$ y old) subjects, more unemployed and retired persons than workers than the general population. Cerebrovascular diseases, disease of the central nervous system (mostly mood disorders, 12 times more frequent), heart diseases, and diseases of the musculoskeletal system were on average twice more prevalent in 
this subcategory. This epidemiological study highlights the differential diagnoses of IH. The prevalence of DSM-IV hypersomnia disorder in this sample was $0.5 \%(0.4-0.6 \%),{ }^{5}$ which suggests that IH is underdiagnosed.

\section{The spectrum of sleepiness in IH}

Although all patients with IH are sleepy, the quality of daytime sleepiness varies among them. Sleepiness ranges from frequent, brief, irresistible and restorative naps (as in narcolepsy) to continuous drowsiness, culminating in rare, prolonged and non-restorative naps (Table 1). Many IH patients, particularly those with long sleep time, describe rare if any daytime sleep attacks. ${ }^{6}$ When naps are taken, $87 \%$ of $\mathrm{IH}$ patients report a nap duration longer than $60 \mathrm{~min} .52$ to $78 \%$ consider their naps unrefreshing, to the point that many patients avoid the situation to prevent severe post-napping inertia. IH patients often report suffering from a continuous non-imperative sleepiness, which leads them to never feel fully awake during the daytime, to feel "foggy" and lack alertness. In patients with sleep drunkenness, this drowsiness is maximal upon awakening and may transiently fade in the evening. ${ }^{6}$ Consequently, IH patients are more alert in the evening than in the morning. ${ }^{6}$ Although the descriptions of sleepiness appear different in IH than in narcolepsy type 1, both groups have on average similar scores on the $\mathrm{ESS}^{7}$ and benefit to a similar degree from stimulants such as modafinil, sodium oxybate and mazindol. ${ }^{7-9}$

Maintaining a hyperactive state can help IH patients to resist sleepiness. ${ }^{6}$ This can include any increased motor activity (e.g. standing, walking while learning, speaking continuously) or performing several activities at the same time (e.g. writing while listening, listening to an audio book when doing chores, avoiding falling asleep when reading a book). ${ }^{6}$ Some $\mathrm{IH}$ patients have a rapid, continuous speech during their medical appointment, as if they need to be excited to maintain a sufficient alertness. On average, patients describe that they cannot sustain attention for more than one hour long (vs. almost 4 hours long in controls), suggesting a cognitive fatigability. ${ }^{6}$ This lack of attention can produce automatic behaviors (Table 1). In our clinical practice, however, they are often extremely organized, making "to do lists" (possibly to compensate for sleepiness and forgetfulness) and reacting rapidly and precisely to questions and requests, in sharp contrast with the frequent procrastination and disorganization observed in patients with narcolepsy or attention deficit hyperactivity disorder. Eventually, autonomic symptoms including orthostatic hypotension, headache and Raynaud phenomenon are reported by half of patients with IH. 


\section{Sleep Duration in IH}

The profile of the major sleep episode in IH varies from a normal (e.g., 7-8 h) sleep duration, sometimes with frequent awakenings, to a prolonged (e.g., 10-15 h) sleep duration with a high sleep efficiency, which seems more specific to IH. In ICSD- $2,{ }^{3} \mathrm{IH}$ was divided into two types, with and without long sleep time, defined by whether the usual sleep duration was more or less than $10 \mathrm{~h}$ per night. The two types were later merged in ICSD3 , because the committee considered that there was not enough data yet to demonstrate that these were different entities. However, a recent clustering analysis in a series of patients in Prague (Czech Republic) found two clearly different clusters, with differing nocturnal sleep times, and no clinical difference between patients with IH without long sleep time and those with narcolepsy type $2 .{ }^{10}$ The cut-off of $10 \mathrm{~h}$ of nocturnal sleep for "long sleep time" has not been determined by a specific analysis, but is derived from the sleep duration defining a long sleeper (a person needing more than $10 \mathrm{~h}$ of sleep to feel alert during daytime). In IH series, the frequency of patients usually sleeping more than $10 \mathrm{~h}$ varies from 19 to $58 \%$ (Table 2). The term "long sleep time" in IH refers only to the main sleep period, and does not include any daytime napping periods. Some IH patients will sleep $9 \mathrm{~h}$ during the night and $3 \mathrm{~h}$ during the day, far exceeding this limit of $10 \mathrm{~h}$ when the $24 \mathrm{~h}$ day is considered. During weekdays, sleep duration for IH patients is often constrained by the working schedule, and does not exceed 7-9 $\mathrm{h}$, whereas sleep rebound of 10-18h may occur during the weekend and vacations. The majority of IH patients feel that they sleep very deeply through the night. Frequent sleep disruption is atypical in IH though common in in narcolepsy. ${ }^{2}$ In patients with $\mathrm{IH}$, sleep mentation also varies, from a complete blackout with no memory of anything between the sleep onset and offset, to vivid dreams ( $25 \%$ of patients $\left.{ }^{11}\right)$ and "being tired of dreaming too much". Sleep-related hallucinations (4 to $43 \%$ of patients) and sleep paralysis (10-40\%) are reported in IH series.

\section{Sleep drunkenness is a major feature in $\mathrm{IH}$}

The ability to wake up in the morning for IH patients varies from an easy awakening (as in narcolepsy) to major sleep inertia characterized by a "sleep drunkenness", which can be the main complaint of the IH patients. Sleep drunkenness is conceptualized as a state intermediate to sleep and wake. It seems to be an exacerbation of the normal sleep inertia observed in the normal population, especially during post-deprivation sleep rebound, and in delayed sleep phase syndrome. ${ }^{12}$ With sleep drunkenness, patients may not awaken without several successive, strong alarm clocks, and still may immediately return to sleep. Confusion, slowness, 
incoordination, and aggressiveness are described. Many IH patients with sleep drunkenness report being slow during the first hour after awakening, with a poor sense of time. Parents of IH teenagers report having to shake the patient or pull them away from the bed, as if they would "try to wake up a dead person". The disability associated with sleep drunkenness contributes to tardiness at work or even losing their job. Many patients need to be awakened by another person, making them dependent on others to keep their work schedule. Mothers with IH have significant difficulties awakening when their baby cries, needing some assistance for performing their parental duties during the night. Sleep drunkenness, however, is not a consistent finding in IH, with the symptom reported by 37 to $100 \%$ of patients, depending on series and on the presence of the "long sleep time" phenotype (Table 2). The symptom is independent from sleep time and the presence or absence of slow wave sleep at the end of the night. ${ }^{13}$ Patients with unipolar depression also report difficulties waking up, but compared to IH, this is associated with anhedonia and decreased motivation. The severity of sleep drunkenness makes it more specific to IH. Note that rare patients with narcolepsy with long sleep time (a disorder cumulating symptoms and signs of narcolepsy and of IH with long sleep time) also report sleep drunkenness. ${ }^{14}$

\section{MSLT is normal in most cases of IH with long sleep time}

A striking example in which the MSLT was normal in spite of obviously excessive sleep time was reported by Voderholzer et al (1998). This 16 year old man had a 4 year history of severely increased sleep need, daytime fatigue, and great difficulty waking after $9 \mathrm{~h}$ of nighttime sleep, with hypotonia and dizziness in the morning, and no cataplexy or sleep attacks during daytime. ${ }^{15}$ His mean sleep latency was 11 min despite previously sleeping for $27 \mathrm{~h}$ during $36 \mathrm{~h}$ of monitoring. During longer term monitoring, he slept 19h22/24h (from $11 \mathrm{PM}$ to 6:30 PM the next day, with an 97\% sleep efficiency). This extreme case illustrates the contrast between a measure of daytime sleep onset propensity (MSLT) and a measure of ad libitum sleep (long term sleep monitoring). Ad libitum sleep, measured over 24 to $48 \mathrm{~h}$, may better capture the sleep needs of people in absence of sleep restriction. By definition, the MSLT should be performed after unrestricted sleep (which would allow recognizing the long sleepers), but many sleep laboratories set up a maximal waking time (from 6:30 AM to 8 AM) for organization purposes and because the first MSLT should start after a minimum time of 90 min (i.e. between $8 \mathrm{AM}$ and 9:30 AM). 
To determine the sensitivity of MSLT (MSL $<8 \mathrm{~min}$ ) in patients with $\mathrm{IH}$, one has to compare to a reference standard in reaching the IH diagnosis. Studies have used different approaches, including a clinical assessment of IH with careful exclusion of competing diagnoses, ${ }^{11}$ or a clinical assessment combined with objective criterion, including either a minimal sleep time during ad libitum long term monitoring, ${ }^{13,16}$ or an abnormal potentiation of the GABA-A receptor in CSF. ${ }^{17}$ In other cases, when the mean sleep latency for an MSLT is set as abnormal if $<8 \mathrm{~min}$, patients without this criterion are generally classified as suffering from "subjective hypersomnia". ${ }^{18}$ The Cambridge (UK) group showed that among 72 patients who had a typical clinical phenotype of IH, including those without long sleep time, $49 \%$ did not fulfill the criteria of an MSL $<8$ $\min$.

The Paris (France) group defined patients suffering from IH with long sleep time as sleeping more than $11 \mathrm{~h}$ during ad libitum monitoring of $19 \mathrm{~h}$ (second night and second day) following a habituation first night and a first day with MLST. ${ }^{13}$. In the group with total sleep time longer than $10 \mathrm{~h}$, as many as $71 \%$ did not fulfill the criteria of a mean sleep latency $<8$ min, of which only $17 \%$ had borderline (between 8 and $10 \mathrm{~min}$ ) sleep latencies. ${ }^{13}$ When considering all IH patients (with and without long sleep time), the mean sleep latency was $<8$ min in $61 \%$, still leaving $39 \%$ of $\mathrm{IH}$ patients with normal mean sleep latencies. ${ }^{13}$ In the Bologna group (Italy), it was not possible to infer the frequency of normal mean sleep latency in IH patients, because those with mean sleep latencies $\geq 8$ min were ruled out as suffering from "subjective hypersomnia". ${ }^{18}$ The Montpellier (France) group used a two-step procedure to set up a minimal sleep time per $32 \mathrm{~h}$ of ad libitum monitoring (first night followed by a day and a second night) leading to a lower limit of $19 \mathrm{~h}$ of sleep/32 $\mathrm{h}$ in 37 patients with frank clinical symptoms of IH and MSL $\leq 10 \mathrm{~min} .{ }^{19}$ Among 90 patients with clear cut or probable IH, $29(67.8 \%)$ did not fulfill the criteria of a mean sleep latency $\leq 8 \mathrm{~min}$, despite $>19 \mathrm{~h}$ of sleep during the $36 \mathrm{~h}$ procedure. Repeating the MSLT using a modified procedure by interrupting each nap after 1 min of sleep, which should preserve sleep pressure and decrease the sleep onset latency), in the same group still resulted in 48 (42\%) patients with a mean sleep latency $>8 \mathrm{~min}$.

The Atlanta (USA) group identified a new biological marker in the cerebrospinal fluid (CSF) suggestive of potentiating the GABA-A receptor function. In 7 patients with drug resistant hypersomnia and various initial diagnoses (including long sleeper, narcolepsy type 2, and Kleine-Levin syndrome), the activity at the GABA receptor was increased, despite a mean sleep latency $>8$ min in 5/7 (71\%) patients. ${ }^{17}$ In 16 patients with nonnarcoleptic, drug-resistant hypersomnia and GABA-A receptor potentiation, 6/16 (37.5\%) had a normal mean sleep latency at the MSLT. ${ }^{20}$ 


\section{The importance of measuring long sleep time/sleep excess}

These results highlight the importance of measures outside the MSLT to capture the IH sleep characteristics. The word hypersomnia comes from the Greek root "hyper" for "excessive" and the Latin root "somnius" for sleep. Thus, the word means "sleep excess", not excessive daytime sleepiness. In IH, sleep excess is best expressed in unrestricted conditions, such as during the weekend, holidays and in the sleep laboratory, with on average three additional hours slept than during weekdays. ${ }^{6}$ The duration of spontaneous night-time sleep time can be measured during unrestrained polysomnography, however, this would not include the daytime sleep time performed during naps. Hence, several groups have developed procedures aimed at assessing the maximum sleep time that can be produced in unrestrained (often boring) conditions, over periods of time lasting 24 to $48 \mathrm{~h}$.

To avoid potential post-sleep deprivation rebound, the three main procedures include the classical recommendation to visit the sleep laboratory after one to two weeks without sleep deprivation, as assessed by sleep log or actigraphy. However, IH patients with long sleep time hardly sleep more than 7-9 h during weekdays when they work, still leaving them sleep deprived relative to their daily sleep needs, unless tests are performed after one week of vacation with unrestrained sleep. The increased homeostatic need for sleep in IH patients can be partly alleviated by the $48 \mathrm{~h}$ procedure developed in Paris (France,) which includes a habituation night followed by 5-nap MSLT test, during which the patients often sleep, although the mean sleep latency is longer than in narcolepsy patients. Whether home-based studies can replace in-lab procedures is questionable, as normative measures have not been established for these conditions.

So far, three different procedures have been developed to capture sleep excess (Figure 1; Table 3). ${ }^{13,18,19}$ One of the procedures (Bologna, Italy) does not include normative measures. ${ }^{18}$ The shorter procedure is the Paris (France) procedure ( $48 \mathrm{~h})$ and the longest ( $80 \mathrm{~h}$, in two separated periods of $24 \mathrm{~h}$ and $58 \mathrm{~h}$ respectively) is the Montpellier (France) procedure.

The Paris procedure lasts a total of $48 \mathrm{~h}$ in the sleep laboratory and is routinely used to evaluate central hypersomnolence in most French expert centers for hypersomnia. ${ }^{13,14,21}$ In addition to measures obtained during standard polysomnography, the procedure characterizes the "narcoleptic" phenotype (i.e., rapidity to fall asleep during the MSLT and identification of SOREMPs), and the "sleep excess" phenotype (measured by the time slept during the second night and day). Patients undergo a first nighttime polysomnography interrupted at 6:30 
$\mathrm{AM}$, followed by 5 MSLT starting at $8 \mathrm{AM}$, and a second night and day ad libitum monitoring, with uninterrupted naps in the morning and afternoon, stopped at $5 \mathrm{PM}$, which provides an 18 to 20 hour long opportunity to sleep (Figure $1 \mathrm{~A}$ ). In $75 \mathrm{IH}$ patients undergoing the Paris procedure, the sleep time obtained during the $18 \mathrm{~h}$ long term monitoring in the sleep laboratory was very similar to the usual sleep time during holidays and week-ends in patients, suggesting that the procedure is not a completely artificial measure, disconnected from the real world, but is an objective measure. ${ }^{6}$ When measures in IH patients are contrasted with those of age- and sex- matched healthy controls, the cutoff of $11 \mathrm{~h}$ of sleep time has the best sensitivity (72\%) and specificity (97\%). In contrast, a lower cutoff of $10 \mathrm{~h}$ has a sensitivity of $55 \%$ and a specificity of $77 \%$; and a higher cutoff of $11 \mathrm{~h} 30$ is highly specific (100\%) but poorly sensitive (53\%). ${ }^{21}$ Only one in 20 patients with residual sleepiness despite adequately treated sleep apnea syndrome slept more than $11 \mathrm{~h}$ during the same procedure, vs. none of the OSA patients without residual sleepiness and none of the older controls. ${ }^{21}$ Notably, up to $18 \%$ of patients with narcolepsy slept longer than $11 \mathrm{~h}$ during the long term procedure. This form of narcolepsy "with long sleep time" was characterized by less prevalent cataplexy and was more severe in terms of clinical impairment (with more frequent sleep drunkenness and non-refreshing naps) compared to patients with narcolepsy without long sleep time. $^{14}$

The Bologna (Italy) procedure lasts $60 \mathrm{~h}$ in total (Figure $1 \mathrm{~B}$ ), and includes an ad libitum monitoring of sleep during the first $48 \mathrm{~h}$, followed by an MSLT on the third day. ${ }^{18}$ Daytime sleep is not imposed in darkness but is dictated by patient preference. The authors did note that patients with narcolepsy type 1 slept longer during the daytime than those with narcolepsy type 2 or with IH without long sleep time.

The Montpellier (France) procedure starts with standard polysomnography followed by an MSLT (Figure 1 C). ${ }^{19}$ Then depending on the clinical assessment and if there is a borderline sleep latency during the MSLT, patients are scheduled for a second procedure lasting $58 \mathrm{~h}$, beginning with standard polysomnography and followed by a modified MSLT (naps are interrupted after 1 min of sleep, in order to avoid decreasing the homeostatic sleep pressure). Sleep is then monitored during a $32 \mathrm{~h}$ bed rest procedure in darkness, including a second night, a second day and then a third night. Subjects are invited to sleep as long as possible, ad libitum. The authors determined the sleep duration during the $32 \mathrm{~h}$ bed rest period in 32 patients with typical $\mathrm{IH}$ symptoms and mean sleep latencies $<10$ min during the first MSLT, and compared it to 21 healthy controls. A cutoff of $19 \mathrm{~h}$ sleep/32 h monitoring reached the highest sensitivity (92\%) and specificity (86\%) to distinguish both groups. When confining the analysis to the first $24 \mathrm{~h}$ of the $32 \mathrm{~h}$ bed rest, a surrogate cut off of $12 \mathrm{~h}$ of sleep has the highest sensitivity $(100 \%)$ /specificity $(86 \%)$. 
Each procedure has its advantages (measuring ad libitum, unrestrained sleep during 24 to $48 \mathrm{~h}$, ease of implementation) and disadvantages (long duration of testing, availability of normative measures, control of zeitgebers, costs). The three laboratories have a long lasting, unpublished experience with their procedure in other cases (e.g., the $48 \mathrm{~h}$ procedure is applied in 20 patients per week in the Paris laboratory during more than 10 years, leading to more than 8000 patients having followed it), which provides some robustness in the diagnosis. The cutoffs identified across these procedures, interestingly approximate the cutoffs of 11-12 $\mathrm{h}$ during ad libitum sleep that was identified in ICSD-2 as an alternative criterion of IH with long sleep time in absence of an MSLT $<8$ minutes. Thus, more recent, controlled studies appear to have reached similar conclusions to prior clinical experience from old, uncontrolled studies in expert centres. ${ }^{22}$

\section{Mechanisms of IH}

\subsection{Triggers}

The cause of IH remains unknown. Long sleep time associated with daytime drowsiness can be observed in post-traumatic hypersomnia, ${ }^{23}$ post viral hypersomnia and various hypersomnias associated with neurological disorders (including tumors of the diencephalon, Prader-Willi syndrome, ${ }^{24}$ inflammatory disorders), making it important to rule out these causes (e.g., to perform brain MRI, identify head trauma within the last year before hypersomnia onset, and assess for recent viral conversion) before reaching the diagnosis of $\mathrm{IH}$. The onset of IH onset usually progressive, making it difficult to identify a trigger. Severe hypersomnia can suddenly occur in the context of a viral infection (e.g., Epstein-Barr virus, cytomegalovirus) but the symptoms usually improve after a few months. However, some patients remain sleepy for years. Similarly, some patients have hypersomnia since birth or for decades, but seek for medical advice when their life factors change (e.g., raising young children, changing of job schedule), which can jeopardize the previous adjustment to what was not considered yet as a disorder.

\subsection{An abnormal sleep structure?}

Many IH patients sense that their sleep is not normal. In sharp contrast with this feeling, the sleep architecture in IH is classically normal or even "supernormal", with a lower arousal index and higher sleep efficiency than many controls (Table 4). ${ }^{13}$ The general profile of the sleep architecture in IH is to see non-REM 
and REM sleep in the expected proportions (Figure 2) ${ }^{25}$ In various groups of patients with $\mathrm{IH}$, the percentage of $\mathrm{N} 3$ has been found to be unchanged,${ }^{26,27}$ decreased, ${ }^{28}$ or increased. ${ }^{29}$ Notably, some patients with IH display persistent N3 episodes at the end of the night, which is atypical of normal sleepers. The REM sleep has been found to be unchanged,,$^{26,27,29}$ or increased. ${ }^{28}$ This normal or supernormal sleep does not explain why sleep is not restorative of adequate daytime alertness in IH patients.

\subsection{Input from functional brain imaging}

Recently, the Montreal group performed brain scintigraphy in 13 patients with IH and 16 healthy controls, using single photon emission computed tomography with ${ }^{99} \mathrm{mTc}$-ethyl cysteinate dimer. ${ }^{30}$ During wakefulness, IH patients showed regional cerebral blood flow decreases in medial prefrontal cortex and posterior cingulate cortex and putamen, as well as increases in amygdala and temporo-occipital cortices. Lower regional cerebral blood flow in the medial prefrontal cortex correlated with higher daytime sleepiness, as measured by the ESS and the mean sleep latency at the MSLT (Figure 3). The authors make an interesting parallel between this profile of decreased blood flow in the medial prefrontal cortex in awake IH patients, which is also seen during NREM stage N2 sleep in normal subjects. ${ }^{31}$ This seminal work suggests that the wakefulness in IH is an intermediate state between wake and sleep, with a seemingly "asleep" medial prefrontal cortex and posterior cingulate cortex and putamen, and compensatory efforts to promote wakefulness from the amygdala and temporo-occipital cortices.

\subsection{Autoimmunity and inflammation in idiopathic hypersomnia}

The rate of comorbid autoimmune disorder is low $(4 \%)$ in $\mathrm{IH}$, and not different from that of controls. ${ }^{32}$ HLA-DQB $1 * 0602$ has been examined in many IH series, with frequencies varying from 16 to $31 \% .7,8,13,11,33$ There were no difference of HLA DQB $1 * 0602$ frequency between IH patients with or without long sleep time, ${ }^{13}$ and between IH patients and healthy controls. ${ }^{13}$ Measures of other HLA DRB1 and DQB1 alleles (low resolution) did not identify any differences between 61 patients with $\mathrm{IH}$ and 30 controls. ${ }^{13}$ In contrast, in our series of 138 patients with $\mathrm{IH}$, the prevalence of inflammatory disorders, allergies, and the incidence of family members with inflammatory disorders was increased in patients compared with controls, suggesting that inflammation may play a role in some cases of $\mathrm{IH} .{ }^{32}$ 


\subsection{Deficiency of an arousal system?}

Among the arousal systems, in IH there is no deficiency in hypocretin-1 (as there is one in narcolepsy type 1) nor in histamine (which is, as hypocretin, released by a single isolated group of neurons). ${ }^{33}$ In 29 patients with IH (with or without long sleep time), the hypocretin-1 CSF levels were $307 \pm 10 \mathrm{pg} / \mathrm{mL} .{ }^{34} \mathrm{In} 26$ patients with IH without long sleep time, the CSF hypocretin levels were $280.7 \pm 14.8 \mathrm{pg} / \mathrm{mL} .{ }^{35}$ The histamine CSF levels were $161 \pm 29.3 \mathrm{pg} / \mathrm{mL}$, a measure in the range of healthy controls. ${ }^{33}$ These levels were lower $(143.3 \pm$ $28.8 \mathrm{pg} / \mathrm{mL})$ in untreated than treated patients $(259.5 \pm 94.9 \mathrm{pg} / \mathrm{mL})$, as in narcolepsy and in other disorders associated with daytime sleepiness (including obstructive sleep apnea syndrome), suggesting that histamine is an non-specific marker of sleepiness. ${ }^{33}$ In 6 patients with IH, the CSF levels of melanin-concentrating hormone, which is secreted by the hypothalamus and promotes REM sleep, were $104 \pm 26 \mathrm{pg} / \mathrm{mL}$, which was not different from that of healthy controls. ${ }^{36}$ Measures of serotonin, norepinephrine, ${ }^{37}$ epinephrine, glutamate, acetylcholine and their metabolites have been rarely performed in the CSF of IH patients, with difficult to interpret results when studied. ${ }^{37}$ The likelihood that a single bioamine deficiency would specifically affect the arousal system alone is low as these bioamines are released by numerous neuronal systems out of the arousal networks, and are essential for many other brain functions.

\subsection{Production of an endogenous hypnotic factor?}

Recently, the Atlanta (USA) group has produced convincing evidence that some resistant cases of hypersomnia (including IH, narcolepsy type 2, "long sleepers" and subjective hypersomnia) could result from the inappropriate release of an endogenous hypnotic substance, which activate the GABA-A receptors. In support of this hypothesis, the CSF of these patients was applied to GABA-A receptors and was able to displace the normal GABA-A binding. Furthermore, some of these patients benefited from drugs blocking GABA receptors, including flumazenil (commonly used for benzodiazepine overdose) and clarithromycin (an antibiotic which antagonizes the GABA-A receptor). ${ }^{17,20}$ The Montpellier (France) group could not reproduce these results in a group of 15 patients with $\mathrm{IH}^{38}$ 
The more frequent evening chronotype in $\mathrm{IH}^{13}$ as well as the occasional benefit of evening melatonin to reduce sleep drunkenness ${ }^{12,13}$ have led the Czech group to measure the profile of melatonin secretion over $24 \mathrm{~h}$ in IH. ${ }^{39}$ There was a delayed melatonin secretion in 10 patients with $\mathrm{IH}$, which has not been reproduced. In 15 patients with $\mathrm{IH}$, the circadian period length in peripheral skin fibroblast was longer by $0.82 \mathrm{~h}$ than in controls. ${ }^{40}$ This finding suggests a genetic contribution of the circadian system in patients with IH. However, of note is that IH patients do not suffer from delayed sleep phase syndrome, possibly because they try not to shift their sleep onset across nights. This longer circadian period may contribute to the sleep drunkenness observed in these patients.

\subsection{Animal models of idiopathic hypersomnia?}

Animal models have been key for understanding the mechanisms of narcolepsy, however, have been less helpful in the study of IH. In rodents and feline models, the main arousal systems include histamine and hypocretin neurons in the lateral hypothalamus, norepinephrine, glutamate, and dopamine neurons in the brainstem reticular formation, and acetylcholine neurons in the basal forebrain and in the pedunculo-pontine nucleus. ${ }^{41}$ The selective absence of hypocretin or histamine has not been demonstrated to induce sleep excess in animals. Indeed, mice without hypocretin neurons spend as much time asleep as wild type mice (both sleep $57 \%$ of the 24-hr time period), whereas their periods of wakefulness are fragmented by sleep episodes containing occasional SOREMPs. ${ }^{42}$ Mice lacking brain histamine have normal daily sleep duration (accounting for $57 \%$ of the time), but are less stimulated by behavioral challenges such as lights off, a new environment, or food delivery.$^{43}$ In contrast, a lesion of the dorsal norepinephrine bundle in cats causes a long lasting, harmonious, severe hypersomnia with $78 \%$ of time asleep, with 15-27\% REM sleep and 73-85\% NREM sleep. ${ }^{44}$ Lesions of the dopamine neurons in the ventral periaqueductal gray matter cause a $20 \%$ increase of the daily total sleep time in rats, with proportional increases of NREM and REM sleep. ${ }^{45}$

\section{Treatment}

No treatment has yet been approved for IH. Current treatment options are based on consensus from professional sleep societies, and, depending on the country, of advice from expert centers, as in France. ${ }^{46}$ Many 
advances in the treatment of narcolepsy have benefited $\mathrm{IH}$, but without the same extent of improvements of symptoms (e.g. long, unrefreshing naps and of sleep drunkenness ) in IH patients (Table 5).

\subsection{Preventive naps}

In sharp contrast with narcolepsy, naps (even when brief) are rarely beneficial in IH. Rather, they are often followed by sleep drunkenness and fail to restore adequate alertness. The MSLT is a good test to evaluate their benefit. If naps are beneficial during the MSLT, then they can be recommended as part of a care plan (e.g. at school, university and work). However, knowing that the naps were unrefreshing during the MSLT (e.g. "it took me a while to fall asleep and then I was awakened by the nurse which was horrible") is helpful so that this strategy is not included in the treatment plan.

\subsection{Reduction and adaptation of working time}

There are several adjustments which may help patients remain highly functional at work despite suffering from IH. Accommodations by the employer to allow an IH patient to begin work at a later hour (e.g., to sleep an extra hour in the morning, or not to risk being fired because of lateness), or to work from home (e.g., one day working home for every two days at the work place) can be helpful to patients. Living close to the workplace will reduce the fatigue linked to commuting time and to early awakening. Some patients have developed hyperactivity as an counterstrategy to boost their alertness, such as always being active, speaking frequently, standing or not resting. ${ }^{6}$ While these activities can be useful counter strategies, IH patients may need additional rest days separate from vacations, otherwise they may be at risk of exhaustion.

\subsection{Managing to wake up in the morning}

Alarm-clocks, phone calls, bright lights, dawn simulation lights, noises and pets seem insufficient to assist IH patients with sleep drunkenness in waking, ${ }^{6}$ (except in those who have an anxious personality in our experience). Being awoken (and shaken) by another person (parent, spouse, roommate) is efficient, but make IH patients more dependent on others to achieve adequate awakening. ${ }^{6}$ This is particularly problematic for mothers 
with IH to wake up to prepare their children for school, forcing some families to teach their children t be more autonomous in their morning preparation.

\subsection{Reducing sleep drunkenness}

No drug has been approved for sleep drunkenness. The French expert consensus statement mentions that melatonin at $3 \mathrm{mg}$ (or $2 \mathrm{mg}$ slow release melatonin) at sleep onset may be useful in some IH patients to reduce sleep drunkenness. ${ }^{46}$ Sodium oxybate (whether as a single dose at sleep onset or split into an evening and a night dose) substantially mitigated sleep drunkenness in a case series from our center. ${ }^{8}$ Other strategies include prescribing a dose of a stimulant at bedtime after awakening the patient one hour before their usual wakeup time and having them ingest the medication or use a transdermal formulation. ${ }^{12}$ Improvement in sleep drunkenness has been reported in individual cases with transdermal and subcutaneous flumazenil, a nicotine patch, and etilefrine (the latter in a patient with comorbid hypotension). ${ }^{12}$ Bright light therapy rarely dissipates sleep inertia. $^{6}$

\subsection{Increasing daytime alertness}

\subsubsection{Modafinil}

The various drugs prescribed for IH are shown in Table 5. Modafinil was approved from 1994 to 2010 in Europe for IH, until approval was revoked due to the lack of trials by pharmaceutical companies. The mean doses were $367 \pm 140 \mathrm{mg}$ in the US ${ }^{47}, 400 \mathrm{mg}$ in $\mathrm{UK}^{, 11}$ of $318 \pm 192 \mathrm{mg}$ in France ${ }^{7}$ and in $200 \mathrm{mg}$ (fixed dose) in a Germany. ${ }^{48}$

In an open, retrospective series in 104 patients with IH and 126 patients with narcolepsy type 1, modafinil was the first line treatment in $96-99 \%$ of patients. ${ }^{7}$ Similar changes in the ESS were reported between IH and narcolepsy patients $(-2.6 \pm 5.1$ vs. $-3 \pm 5.1)$ and a similar benefit as estimated by the patients and clinicians. However, the change in the ESS was lower in IH patients with long sleep time compared to those without long sleep time. $72 \%$ of IH patients reported a benefit of modafinil on their symptoms, similar to patients with narcolepsy type $1 .^{7}$ In a randomized, double-blind, placebo-controlled study in 33 patients with IH without long sleep time in Germany, the ESS decreased in patients treated with modafinil. ${ }^{48}$ Compared to 
placebo, modafinil decreased sleepiness significantly but did not significantly improve mean sleep latency in the maintenance of wakefulness test. The clinical general impression improved significantly from baseline to the last visit on treatment. In a randomized, placebo controlled crossover trial of modafinil $400 \mathrm{mg} / \mathrm{d}$ in 13 patients with narcolepsy and 14 patients with $\mathrm{IH}$, modafinil treatment was associated with improved driving simulation results. ${ }^{49}$ In this study, mean sleep latency on the maintenance of wakefulness test greatly improved from $19.7 \pm$ $9.2 \mathrm{~min}$ with placebo to $30.8 \pm 9.8 \mathrm{~min}$ with modafinil, but results were not separated by diagnosis. The safety of modafinil was similar between IH and in narcolepsy groups. ${ }^{7}$ For these reasons, modafinil is considered first line treatment in $\mathrm{IH}^{46}$

\subsubsection{Methylphenidate and amphetamines}

Although methylphenidate is frequently used as a second line medication in IH, very few data are published in case series, and no controlled study has been performed (Table 5. Methylphenidate was the first line treatment in IH at the Mayo Clinic (Rochester, MN, USA) until 1998, when modafinil emerged. ${ }^{47}$ The mean dose of methylphenidate was $50.9 \pm 27.3 \mathrm{mg} / \mathrm{d}$ in 61 patients, of whom 40 took as monotherapy. Patients took 3 to 4 doses per day using the immediate release form, but many patients took a combination of immediate and slow release forms. Twenty one (52\%) patients were considered as complete responders (ESS reduction of -9 points on average), 13 (33\%) patients were partial responders (ESS reduction of -6 points on average), and 2 (5\%) patients did not respond to the drug. In total, $95 \%$ of patients were responders to methylphenidate vs. $88 \%$ to modafinil $(\mathrm{p}=0.29) .{ }^{47}$

The use of dextroamphetamine $(35.7 \pm 44.4 \mathrm{mg} / \mathrm{d})$, metamphetamine $(36 \pm 17 \mathrm{mg} / \mathrm{d})$ and combination of amphetamine and dextroamphetamine $(79.3 \pm 30.6 \mathrm{mg} / \mathrm{d})$ in IH has been reported in the $\mathrm{UK}^{11}$ and in the US, ${ }^{47}$ alone or in combination with modafinil or methylphenidate, with $25 \%$ to $52 \%$ of responders, depending on the criteria used to define responders (Table 5). Pemoline $(66.9 \pm 36.6 \mathrm{mg} / \mathrm{d})$ was used in 7 patients with $3(43 \%)$ responders. ${ }^{47}$ Mazindol is a pseudo-amphetamine which has been developed for losing weight in obese children and was efficacious in open trials in narcolepsy and in cataplexy. ${ }^{9}$ In 37 patients with IH resistant to two drugs,

the ESS fell from $17 \pm 4.4$ to $12.5 \pm 5.1$ under treatment with mazindol (maximum dose in patients $3.6 \pm 1.2$ mg). ${ }^{9}$ The benefit was similar if not larger than in patients with narcolepsy. The last company producing mazindol stopped its production in 2016 for insufficient sales. 


\subsubsection{Pro-histamine drugs}

Pitolisant is a new anti-H3 agonist, which blocks the presynaptic reuptake of histamine and increases its release in the brain, which was developed and approved in narcolepsy. ${ }^{50}$ Our group has used this medication in 65 patients with IH resistant to three other medications and observed a beneficial, alerting effect in one third of the patients (Table 5).$^{51}$ The side effects were rare and benign. They included gastralgia, increased appetite, headache, insomnia and anxiety.

\subsubsection{Sodium oxybate}

Sodium oxybate (which stimulates GABA-A receptors in the brain) is approved as a treatment of narcolepsy. Daytime sleepiness is reduced when using two doses per night, reduces cataplexy and improves the dyssomnia. The rationale for using sodium oxybate in IH was not obvious at first, as IH patients sleep well (instead of suffering from dyssomnia) and are difficult to awaken. However, in a single center, open-label trial of sodium oxybate in our center of $46 \mathrm{IH}$ patients with no benefits from modafinil, methylphenidate and amphetamine (Table 4), sodium oxybate resulted in similar benefits as observed in narcolepsy, even when using a lower dose (a single dose at bedtime). ${ }^{8}$ The side effects were similar to those observed in narcolepsy, but more frequent in the IH group. Half of the patients with IH stopped sodium oxybate because of disabling nausea and dizziness.

\subsection{Reducing daytime drowsiness}

\subsubsection{Flumazenil}

Following the discovery of a possible, endogenous peptide enhancing GABA-A transmission in the CSF of several patients with IH, the Atlanta (USA) group developed strategies aimed at blocking the GABA-A receptors to counteract the action of such a hypnotic peptide. The first candidate was flumazenil, which is commonly used as an antidote for benzodiazepine intoxication. Intravenous flumazenil has a short half-life, and intravenous continuous infusions of flumazenil ( 0.38 to $2 \mathrm{mg}$ ) were needed in their first trial to improve the psychomotor 
vigilance test (PVT) in a series of 7 patients with various (IH, narcolepsy type 2, long sleepers, Kleine-Levin syndrome) hypersomnias. ${ }^{17}$ The same group developed sublingual and transdermal forms of flumazenil, in order to avoid the immediate destruction of the drug by the liver. Among $36 \mathrm{IH}$ patients with treatment-refractory sleepiness, $23(64 \%)$ were initial responders to flumazenil (-5 points on ESS). ${ }^{52}$ In the full group of treated patients (which included patients with narcolepsies, IH, subjective hypersomnolence and sleep apnea with hypersomnolence), flumazenil responders were more often women and subjects with sleep inertia. ${ }^{52}$ The most common side effect was dizziness. Approximately one third of initial responders discontinued flumazenil for various reasons (tolerance, price, etc.). ${ }^{52}$

\subsubsection{Clarithromycin}

These investigators have also looked for oral drugs which have anti-GABA effects. The antibiotic, penicillin, is known to block the GABA receptors and may induce seizure for this effect. The group found that another common antibiotic, clarithromycin, used as a single morning dose of 500-1000 mg/d, reduced subjective sleepiness (but did not change PVT) in a randomized, cross-over, double-blind, placebo controlled study in IH patients with CSF evidence of endogenous GABA-A receptor activating peptide (Table 5) ${ }^{20}$ Clarithromycin may induce a bad taste, and may expose to changes in vaginal and gut flora (mitigated by the use of probiotics), but it is easily available and inexpensive to try determine if there is a short- and long-term benefit for an IH patient. In a longer term study of clarithromycin in 53 patients with IH, 64\% reported initial improvement in subjective sleepiness and $38 \%$ elected to continue clarithromycin therapy for the long term. ${ }^{53}$

\section{Conclusion}

Idiopathic hypersomnia is a devastating and poorly studied disorder, affecting women more often than men. The disorder has not received sufficient medical attention or adequately powered treatment studies due in part to the rarity of the disorder and difficulties with diagnosis. However, recent advances in precision medicine suggest that the disorder can be better characterized in many patients with the use of prolonged protocols rather than the MSLT. The development of home based monitoring systems, measuring appropriate surrogates of sleep may be a future approach to support the IH diagnosis. Standardized approaches to medication treatment have developed. The identification of a benzodiazepine-like endogenous peptide in some IH patients with stimulant-refractory sleepiness paves the way for treating these ones with benzodiazepine antagonists like flumazenil and 
clarithromycin. Since the prevalence of IH is close to that of narcolepsy, this should motivate pharmaceutical companies to develop drugs targeted for this disorder.

\section{References}

1. Roth B. Narcolepsy and hypersomnia. Basel: Karger; 1980.

2. American Sleep Disorders Association. The International Classification of Sleep Disorders. Diagnosis and Coding Manual. Rochester1990.

3. American Academy of Sleep Medicine. The International Classification of Sleep Disorders - Revised. Chicago, IL: American Academy of Sleep Medicine; 2005.

4. American Academy of Sleep Medicine. The international Classification of Sleep Disorders, 3rd edition. Darien, IL: American Academy of Sleep Medicine; 2014.

5. Ohayon M, Reynolds CI, Dauvilliers Y. Excessive sleep duration and quality of life. Annals of neurology. 2013;73:785-794.

6. Vernet C, Leu-Semenescu S, Buzare M, Arnulf I. Subjective symptoms in idiopathic hypersomnia: beyond excessive sleepiness. J Sleep Res. 2010;19(4):525-534.

7. Lavault S, Dauvilliers Y, Drouot X, et al. Benefit and risk of modafinil in idiopathic hypersomnia vs. narcolepsy with cataplexy. Sleep medicine. 2011;12(6):550-556.

8. Leu-Semenescu S, Louis P, Arnulf I. Benefits and risk of sodium oxybate in idiopathic hypersomnia versus narcolepsy type 1: a chart review. Sleep medicine. 2016;7:38-44.

9. Nittur N, Konofal E, Dauvilliers Y, et al. Mazindol in narcolepsy and idiopathic and symptomatic hypersomnia refractory to stimulants: a long-term chart review. Sleep medicine. 2013;14(1):30-36.

10. Sonka K, Susta M, Billiard M. Narcolepsy with and without cataplexy, idiopathic hypersomnia with and without long sleep time: a cluster analysis. Sleep medicine. 2015;16(2):225-231.

11. Anderson K, Pilsworth S, Sharples L, Smith I, Shneerson J. Idiopathic hypersomnia: a study of 77 cases. Sleep. 2007;30:1274-1281.

12. Trotti L. Waking up is the hardest thing I do all day: Sleep inertia and sleep drunkenness. Sleep medicine. 2017;35:78-84.

13. Vernet C, Arnulf I. Idiopathic hypersomnia with and without long sleep time: a controlled series of 75 patients. Sleep. 2009;32(6):752-759.

14. Vernet C, Arnulf I. Narcolepsy with long sleep time: a specific entity? Sleep. 2009;32(9):1229-1235.

15. Voderholzer U, Backhaus J, Hornyak M, Hohagen F, Berger M, Riemann D. A 19-h spontaneous sleep period in idiopathic central nervous system hypersomnia. J Sleep Res. 1998;7:101-103.

16. Evangelista E, Lopez R, Barateau L, et al. Alternative diagnostic criteria for idiopathic hypersomnia: A 32-hour protocol. Annals of neurology. 2018;in press.

17. Rye DB, Bliwise DL, Parker K, et al. Modulation of vigilance in the primary hypersomnias by endogenous enhancement of GABAA receptors. Sci Transl Med. 2012;4(161):161ra151.

18. Pizza F, Moghadam K, Vandi S, et al. Daytime continuous polysomnography predicts MSLT results in

hypersomnias of central origin. J Sleep Res. 2013;22:32-40.

19. Evangelista E, Lopez R, Barateau L, et al. Alternative diagnostic criteria for idiopathic hypersomnia: A 32-hour protocol. Annals of neurology. 2018;83(2):235-247.

20. Trotti L, Saini P, Bliwise D, Freeman A, Jenkins A, Rye D. Clarithromycin in $\gamma$-aminobutyric acidRelated hypersomnolence: A randomized, crossover trial. Annals of neurology. 2015;78:454-465.

21. Vernet C, Redolfi S, Attali V, et al. Residual sleepiness in obstructive sleep apnoea: phenotype and related symptoms. Eur Respir J. 2011;38(1):98-105.

22. Billiard M, Merle C, Carlander B, Ondze B, Alvarez D, Besset A. Idiopathic hypersomnia. Psychiatry Clin Neurosci. 1998;52(2):125-129.

23. Imbach LL, Valko PO, Li T, et al. Increased sleep need and daytime sleepiness 6 months after traumatic brain injury: a prospective controlled clinical trial. Brain. 2015;138(Pt 3):726-735.

24. Ghergan A, Coupaye M, Leu-Semenescu S, et al. Prevalence and Phenotype of Sleep Disorders in 60 Adults With Prader-Willi Syndrome. Sleep. 2017;40:doi: 10.1093/sleep/zsx1162.

25. American Academy of Sleep Medicine. International classification of sleep disorders, $2^{\text {nd }}$ ed.: Diagnostic and coding manual. Westchester, Illinois: American Academy of Sleep Medicine; 2005. 
26. Bassetti C, Aldrich M. Idiopathic hypersomnia. A series of 42 patients. . Brain. 1997;120(8):14231435 .

27. Vernet C, Arnulf I. Idiopathic hypersomnia with and without long sleep time: a controlled series of 75 patients. Sleep. 2009;32(6):753-759.

28. Sforza E, Gaudreau H, Petit D, Montplaisir J. Homeostatic sleep regulation in patients with idiopathic hypersomnia. Clinical neurophysiology : official journal of the International Federation of Clinical Neurophysiology. 2000;111(2):277-282.

29. Anderson KN, Pilsworth S, Sharples LD, Smith IE, Shneerson JM. Idiopathic hypersomnia: a study of 77 cases. Sleep. 2007;30(10):1274-1281.

30. Boucetta S, Montplaisir J, Zadra A, et al. Altered Regional Cerebral Blood Flow in Idiopathic Hypersomnia. Sleep. 2017;40(10).

31. Dang-Vu T, Desseilles M, Laureys S, et al. Cerebral correlates of delta waves during non-REM sleep revisited. Neuroimage. 2005;28:14-21.

32. Barateau L, Lopez R, Arnulf I, et al. Comorbidity between central disorders of hypersomnolence and immune-based disorders. Neurology. 2017;88:93-100.

33. Kanbayashi T, Kodama T, Kondo H, et al. CSF histamine contents in narcolepsy, idiopathic hypersomnia and obstructive sleep apnea syndrome. Sleep. 2009;32(2):181-187.

34. Mignot E, Lammers GJ, Ripley B, et al. The role of cerebrospinal fluid hypocretin measurement in the diagnosis of narcolepsy and other hypersomnias. Arch Neurol. 2002;59(10):1553-1562.

35. Kanbayashi T, Inoue Y, Chiba S, et al. CSF hypocretin-1 (orexin-A) concentrations in narcolepsy with and without cataplexy and idiopathic hypersomnia. J Sleep Res. 2002;11(1):91-93.

36. Peyron C, Valentin F, Bayard S, et al. Melanin concentrating hormone in central hypersomnia. Sleep medicine. 2011;12:768-772.

37. Montplaisir J, de Champlain J, Young SN, et al. Narcolepsy and idiopathic hypersomnia: biogenic amines and related compounds in CSF. Neurology. 1982;32(11):1299-1302.

38. Dauvilliers Y, Evangelista E, Lopez R, et al. Absence of $\gamma$-aminobutyric acid-a receptor potentiation in central hypersomnolence disorders. . Annals of neurology. 2016;80:259-268.

39. Nevsimalova S, Blazejova K, Illnerova H, et al. A contribution to pathophysiology of idiopathic hypersomnia. Suppl Clin Neurophysiol. 2000;53:366-370.

40. Materna L, Halfter H, Heidbreder A, et al. Idiopathic hypersomnia patients revealed longer circadian period length in peripheral skin fibroblasts. Frontiers in neurology. 2018;9:424.

41. Saper CB, Scammell TE, Lu J. Hypothalamic regulation of sleep and circadian rhythms. Nature. 2005;437(7063):1257-1263.

42. Hara J, Beuckmann CT, Nambu T, et al. Genetic ablation of orexin neurons in mice results in narcolepsy, hypophagia, and obesity. Neuron. 2001;30(2):345-354.

43. Parmentier R, Ohtsu H, Djebbara-Hannas Z, Valatx JL, Watanabe T, Lin JS. Anatomical, physiological, and pharmacological characteristics of histidine decarboxylase knock-out mice: evidence for the role of brain histamine in behavioral and sleep-wake control. The Journal of neuroscience : the official journal of the Society for Neuroscience. 2002;22(17):7695-7711.

44. Petitjean F, Sakai K, Blondaux C, Jouvet M. [Hypersomnia by isthmic lesion in cat. II. Neurophysiological and pharmacological study]. Brain Res. 1975;88(3):439-453.

45. Lu J, Jhou T, Saper C. Identification of wake-active neurones in the ventral periaqueducal gray matter. The Journal of neuroscience : the official journal of the Society for Neuroscience. 2006;26(1):193-202.

46. Lopez R, Arnulf I, Drouot X, Lecendreux M, Dauvilliers Y. French consensus. Management of patients with hypersomnia: Which strategy? Rev Neurol (Paris). 2017;173:8-18.

47. Ali M, Auger R, Slocumb N, Morgenthaler T. Idiopathic hypersomnia: clinical features and response to treatment. J Clin Sleep Med. 2009;5:562-568.

48. Mayer G, Benes H, Young P, Bitterlich M, Rodenbeck A. Modafinil in the treatment of idiopathic hypersomnia without long sleep time--a randomized, double-blind, placebo-controlled study. J Sleep Res. 2015;24:74-81.

49. Philip P, Chaufton C, Taillard J, et al. Modafinil improves real driving performance in patients with hypersomnia: a randomized double-blind placebo-controlled crossover clinical trial. Sleep. 2014;37(3):483487.

50. Dauvilliers Y, Bassetti C, Lammers GJ, et al. Pitolisant versus placebo or modafinil in patients with narcolepsy: a double-blind, randomised trial. Lancet Neurol. 2013;12:1068-1075.

51. Leu-Semenescu S, Nittur N, Golmard J, Arnulf I. Effects of pitolisant, a histamine H3 inverse agonist, in drug-resistant idiopathic and symptomatic hypersomnia: a chart review. Sleep medicine. 2014;15:681-687.

52. Trotti LM, Saini P, Koola C, LaBarbera V, Bliwise DL, Rye DB. Flumazenil for the Treatment of Refractory Hypersomnolence: Clinical Experience with 153 Patients. J Clin Sleep Med. 2016;12(10):13891394. 
53. Trotti L, Saini P, Freeman A, et al. Improvement in daytime sleepiness with clarithromycin in patients with GABA-related hypersomnia: Clinical experience. J Psychopharmacol. 2013.

54. Ozaki A, Inoue Y, Hayashida K, et al. Quality of life in patients with narcolepsy with cataplexy, narcolepsy without cataplexy, and idiopathic hypersomnia without long sleep time: comparison between patients on psychostimulants, drug-naive patients and the general Japanese population. Sleep medicine. 2012;13(2):200-206.

55. Pizza F, Ferri R, Poli F, Vandi S, Consentino F, Plazzi G. Polysomnographic study of nocturnal sleep in idiopathic hypersomnia without long sleep time. J Sleep Res. 2013;22:185-196.

56. Sasai T, Inoue Y, Komada Y, Sugiura T, Matsushima E. Comparison of clinical characteristics among narcolepsy with and without cataplexy and idiopathic hypersomnia without long sleep time, focusing on HLADRB1*1501/DQB1*0602 finding. Sleep medicine. 2008;10:961-966.

57. Vignatelli L, D'Alessandro R, Mosconi P, et al. Health-related quality of life in Italian patients with narcolepsy: the SF-36 health survey. Sleep medicine. 2004;5:467-475.

58. Barateau L, Jaussent I, Lopez R, et al. Smoking, Alcohol, Drug Use, Abuse and Dependence in Narcolepsy and Idiopathic Hypersomnia: A Case-Control Study. Sleep. 2016;39(3):573-580.

59. Takei Y, Komada Y, Namba K, et al. Differences in findings of nocturnal polysomnography and multiple sleep latency test between narcolepsy and idiopathic hypersomnia. Clinical neurophysiology : official journal of the International Federation of Clinical Neurophysiology. 2012;123:137-141.

60. Bastuji H, Jouvet M. Successful treatment of idiopathic hypersomnia and narcolepsy with modafinil. Prog Neuro-Psychopharmacol Biol Psychiat. 1988;12:695-700.

61. Leu-Semenescu S, Louis P, Arnulf I. Benefits and risk of sodium oxybate in idiopathic hypersomnia versus narcolepsy type 1: a chart review. Sleep Med. 2015.

62. Trotti LM, Saini P, Bliwise DL, Freeman AA, Jenkins A, Rye DB. Clarithromycin in gammaaminobutyric acid-Related hypersomnolence: A randomized, crossover trial. Annals of neurology. 2015;78(3):454-465. 
Table 1: Symptoms in idiopathic hypersomnia

1) Excessive daytime sleepiness

- Continuously drowsiness/fogginess without naps

- $\quad$ Single vs. repeated daytime naps

- $\quad$ Brief (e.g., <30-60 min) vs. prolonged naps

- $\quad$ Restorative vs. non-restorative naps

- $\quad$ Irresistible (e.g., sleep attacks) vs. resistible sleep episodes

- $\quad$ Hyperactive counterstrategy

3) Associated symptoms

- Automatic behaviors

- Trouble focusing

- Sleep related hallucinations

- Sleep paralysis

- Orthostatic hypotension

- Raynaud phenomenon

- Headaches

\section{2) Nighttime sleep}

- $\quad$ Normal vs. long (>10h) duration (during unrestrained conditions)

- $\quad$ High vs. normal or low sleep efficiency

- Dream recall: absent (“black out”), normal, excessive

- $\quad$ Sleep inertia: none, mild, or severe (sleep drunkenness)

\section{4) Epidemiology}

- $\quad$ Rare neonatal forms

- Mostly young adult onset

- $\quad$ Women > men

- $\quad$ More evening chronotype 
Table 2. Demographical and clinical features in various series of patients with

idiopathic hypersomnia

Measure

Idiopathic hypersomnia

(mixed)
IH without LST

IH with LST

(a)

Demographical features

Age at onset, y

Age at diagnosis, y

Sex ratio, female/male

Caucasian ethnicity, \%

Body mass index, $\mathrm{Kg} / \mathrm{m}^{2}$

Circadian score

\section{Daytime symptoms}

Score at the Epworth sleepiness

scale at diagnosis, 0-24

$$
\begin{aligned}
& 17 \pm 9^{11} ; 17.5-18^{48} ; 20[16]^{47} ; \quad 16^{19} ; 19 \pm 7^{54} ; 22^{26} ; \quad 16^{19} ; 21 \pm 9^{10} \\
& 22 \pm 9^{8} ; 22 \pm 12^{7} \quad 22 \pm 13^{18} \\
& 24^{26} \\
& 29 \pm 10^{10}
\end{aligned}
$$

$$
\begin{aligned}
& 29 \pm 12^{8} ; 33 \pm 13^{7} ; 34 \pm 12^{11} ; \quad 32^{19} ; 34 \pm 13^{13} \quad 27^{19} ; 34 \pm 13^{13} \\
& 34 \pm 13^{13} ; 34[16]^{47} ; 35^{26}
\end{aligned}
$$$$
38^{48} ; 51^{11} ; 64^{13} ; 64^{26}
$$$$
42^{18} ; 44^{26} ; 49^{54} ; 60
$$$$
63^{26} ; 68^{13} ; 73^{10} \text {; }
$$$$
65^{47} ; 74^{7} ; 77^{30} ; 78^{8}
$$$$
{ }^{10,13} ; 82^{19}
$$$$
79^{19}
$$

$$
93^{26} ; 100^{13}
$$

$$
24 \pm 5^{7},{ }^{13} ; 25[4]^{11} ; 25.4[6.2]
$$

$$
22^{19} ; 25.2 \pm 3.6^{55} \text {; }
$$$$
22^{19} ; 23 \pm 4^{13}
$$$$
\text { 47 } 25-26^{48}
$$$$
26 \pm 5^{13}
$$

$$
48 \pm 13^{13} ; 49 \pm 8^{30}
$$

$$
53 \pm 10^{13}
$$

$$
44 \pm 14^{13}
$$


Total daytime sleep, min

Sleep attacks, $\%$

Long (>30 min) naps, \%

Nap longer than 60 min, \%

Refreshing short naps, \%

Non refreshing naps, \%

Attention complaint, \%

Memory complaint, \%

Automatic behaviors, $\%$

\section{Night-time symptoms}

Usual sleep duration, $\mathrm{h}$

Usual sleep time $>10 \mathrm{~h}, \%$

Sleep paralysis, $\%$

Hypnagogic hallucination, $\%$

Difficulty waking up in the

morning, \%

Sleep drunkenness, $\%$

Time to get going in the morning, min

$$
90 \pm 56^{13}
$$

$$
54^{26}
$$

$51^{26}$

$87^{11}$

$25^{6}$

$52^{6} ; 72^{47} ; 77^{26} ; 78^{11}$

$55^{6}$

$79^{6}$

$$
58^{6} ; 61^{26}
$$

$63^{26}$

$38^{26}$
$8[1]^{47} ; 8.4 \pm 1.9^{26} ; 9 \pm 2^{11}$

$$
19^{47} ; 30^{11} ; 58^{7}
$$

$10^{47} ; 28^{13} ; 40^{26}$

$4^{47} ; 4.5^{11} ; 24^{13} ; 43^{26}$

$66^{47} ; 100^{8}$

$37^{13} ; 55^{11} ; 66^{47}$

$0^{10} ; 11^{26} ; 23^{13} ; 46^{11}$

$36^{26} ; 50^{13} ; 70^{11}$;

$58.3^{10}$

$42^{26}$

$7 \pm 6^{26}$

$72 \pm 62^{26}$

\section{Comorbidities}


Migraine, \%

Minor depression, \%

HAD depression score

Orthostatic hypotension,

headache, Raynaud, \%

Allergy, \%

Autoimmune disease, $\%$

Inflammatory disease, $\%$

Heavy alcohol drinker, \%

Tobacco smoker, $\%$

Substance use, $\%$
$7-12^{26} ; 8^{11}$

$14^{11}$

$7.1 \pm 5$ (> controls $)^{13}$

$7.5 \pm 4.6^{13}$

$6.8 \pm 5.4^{13}$

$46^{6} ; 50^{26}$

$4^{32}$

$7^{32}$

$9^{58}$

$20^{58}$

$2^{58}$

HAD: Hospital Anxiety and Depression rating scale 
Table 3. Extended Sleep Monitoring Procedures

\begin{tabular}{|c|c|}
\hline $\begin{array}{l}\text { Paris } \\
\text { Procedure }{ }^{13,14,21}\end{array}$ & $\begin{array}{l}\text { Main protocol } \\
\text { - Night 1: Full polysomnography till 6:30AM } \\
\text { - Day 1: 5-nap MSLT starting at 8AM } \\
\text { - Night 2: ad libitum } \\
\text { Notes: } \\
\text { - Dinner at 7PM on the first night } \\
\text { - TV, computer, and visits from friends prohibited } \\
\text { - Books, newspapers, watches, and daylight allowed } \\
\text { - 2nd night of ad libitum sleep } \\
\circ \text { Patient' sleep is not interrupted } \\
\circ \quad \text { Patient decides when to sleep and switch off lights } \\
\circ \quad \text { Patient decides when to wake up the next day } \\
\text { - Patients recommended to take } 2 \text { naps in a darkened room } \\
\circ \text { One in the morning } \\
\circ \text { One in the afternoon } \\
\circ \text { Stopped after } 30 \text { minutes if patient cannot fall asleep } \\
\circ \text { Continued if they do fall asleep until the patient wakes up } \\
\text { - Meals provided }\end{array}$ \\
\hline $\begin{array}{l}\text { Bologna } \\
\text { Procedure }{ }^{18} \\
\text { (60h protocol) }\end{array}$ & $\begin{array}{l}\text { Main protocol } \\
\text { - Ad libitum sleep for the first } 48 \mathrm{~h} \\
\text { Notes on the } 3^{\text {rd }} \text { day } \\
\text { - Patient may move around, read, and watch TV } \\
\text { Amount of daytime sleep is determined by the patient }\end{array}$ \\
\hline $\begin{array}{l}\text { Montpellier } \\
\text { Procedure }{ }^{19} \\
\text { (80h protocol) }\end{array}$ & $\begin{array}{l}\text { Main protocol } \\
\text { - Night 1: Full polysomnography } \\
\text { - Day 1: 5-nap MSLT } \\
\text { If borderline sleep latency on the MSLT: } \\
\text { - Night 2: Full polysomnography } \\
\text { - Day 2: modified 5-nap MSLT (patient is awoken after } 1 \text { minute of } \\
\text { - } \quad \text { Nleep) }\end{array}$ \\
\hline
\end{tabular}




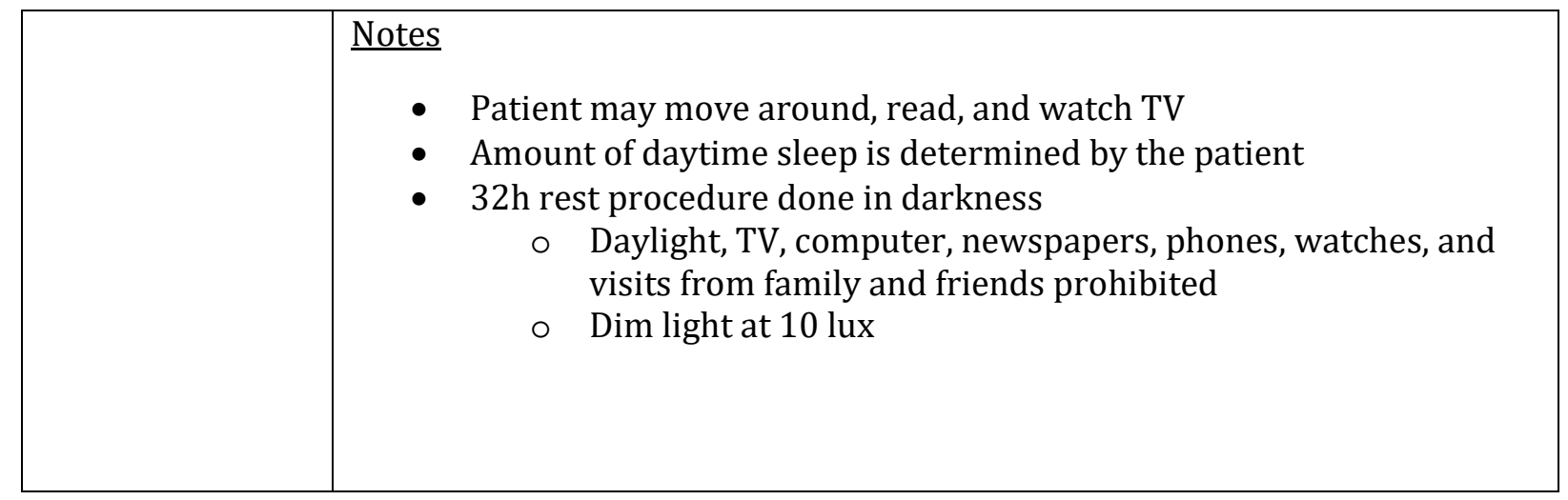


Table 4. Sleep Measures in idiopathic hypersomnia

\begin{tabular}{|c|c|c|c|}
\hline Measure & IH unspecified & IH without LST & IH with LST \\
\hline \multicolumn{4}{|c|}{ Multiple sleep latency test (MSLT) and maintenance of wakefulness test (MWT) } \\
\hline $\mathrm{MSL}<8 \mathrm{~min}, \%$ & $44^{8} ; 51^{11} ; 61^{13}$ & $68 ; 100{ }^{13}$ & $11^{19} ; 29^{13}$ \\
\hline \multirow[t]{4}{*}{ MSL, min } & $4.3 \pm 2.1^{26} ; 4.8[2.5]^{47}$ & $4.3 \pm 1.1^{26} ; 5.6 \pm 0.3^{13}$ & $3.9 \pm 2.4^{26} ; 8.9 \pm 3.5^{11}$ \\
\hline & $5.8-5.9^{26} ; 7.3 \pm 3.2^{30}$ & $5.9+1.1^{18} ; 6.1 \pm 3.4^{10}$ & $9.6 \pm 0.7^{13} ; 9.8^{19}$ \\
\hline & $7.8 \pm 0.5^{13} ; 8.3 \pm 3.1^{11}$ & $7.9 \pm 2.6^{11}$ & $10.2 \pm 4^{10}$ \\
\hline & $9.3 \pm 3.8^{8}$ & & \\
\hline SOREMP, No & $0.2+0.4^{30}$ & $0.2 \pm 0.4^{10,18}$ & $0.2 \pm 0.4^{10}$ \\
\hline MWT latency, $20 \mathrm{~min}$ & $12.5-13.5^{26}$ & - & - \\
\hline
\end{tabular}

\section{Nighttime polysomnography}

Sleep onset latency, min

$$
\begin{gathered}
7[9]^{47} ; 12 \pm 8^{11} ; 18-19^{26} ; \\
24 \pm 21^{8} ; 31 \pm 42^{13}
\end{gathered}
$$$$
7^{19} ; 8 \pm 7^{59}
$$$$
10^{19} ; 35 \pm 51^{13}
$$$$
9 \pm 9^{55} ; 27 \pm 27^{13}
$$

REM sleep latency, min

$$
82[55]^{47} ; 82 \pm 48^{13} ; 106 \pm 59^{8}
$$

$$
69 \pm 42^{55 ;} 74^{19}
$$$$
69^{19} ; 81 \pm 44^{13}
$$

$$
83 \pm 53^{13} ; 97 \pm 53^{59}
$$

Sleep efficiency, \% of

$90[8]^{47} ; 91 \pm 6^{13} ; 91 \pm 15^{8} ;$
$92^{26} ; 93 \pm 5^{26} ; 94 \pm 4^{11}$

$87 \pm 6^{55} ; 89 \pm 5^{26}$

$92 \pm 6^{13 ;} ; 92.7^{19}$

total sleep time

$89 \pm 7^{13} ; 91 \pm 5^{59 ;} 94$

$96 \pm 2^{26}$

19

Total sleep time, min

$$
\begin{aligned}
& 392-420^{26} ; 454[62]^{47} \\
& 481 \pm 85^{8} ; 579 \pm 90^{13}
\end{aligned}
$$$$
428 \pm 63^{55} ; 441 \pm 23^{26}
$$$$
449^{19} ; 490 \pm 50^{26} ;
$$

$446^{19} ; 489 \pm 46^{59}$

$633 \pm 76^{13}$ 


$$
517 \pm 60^{13}
$$

Sleep stages, $\%$ of total sleep time

\begin{tabular}{|c|c|c|c|}
\hline Stage N1 & $4 \pm 2^{8}, 6[4]^{47}$ & $4^{19} ; 11 \pm 7^{59}$ & $4^{19}$ \\
\hline Stage N2 & $50 \pm 7^{8} ; 56[10]^{47}$ & $53 \pm 8^{59} ; 56^{19}$ & $55^{19}$ \\
\hline \multirow[t]{2}{*}{ Stage N3 } & $8 \pm 5^{26} ; 15[8]^{47} ; 18-27^{26}$ & $6 \pm 6^{26} ; 9 \pm 8^{54}$ & $9 \pm 6^{26} ; 20^{19} ; 21 \pm 9^{13}$ \\
\hline & $21 \pm 8^{13} ; 26 \pm 8^{8}$ & $21^{19} ; 21 \pm 8^{13}$ & \\
\hline \multirow[t]{2}{*}{ Stage R } & $18 \pm 7^{26} ; 20-21^{26} ; 21 \pm 5^{8}$ & $14 \pm 7^{26} ; 17^{19}$ & $20^{19} ; 22 \pm 4^{26}$ \\
\hline & $22[8]^{47} ; 24 \pm 7^{13}$ & $21 \pm 5^{59} ; 23 \pm 5^{13}$ & $24 \pm 7^{13}$ \\
\hline
\end{tabular}

Analysis of sleep microstructure

Arousal index, n/h

$9 \pm 6^{13} ; 10 \pm 5^{8}$

$10 \pm 7^{13}$

$7 \pm 4^{13}$

PLMS index, $\mathrm{n} / \mathrm{h}$

$1[4]^{47} ; 3^{26} ; 3 \pm 3^{8} ; 9 \pm 13^{13}$

$0^{19} ; 1 \pm 4^{59} ; 7 \pm 7^{55}$

$0.3^{19} ; 5 \pm 8^{13}$

$11 \pm 15^{13}$

\section{Long term sleep, ad libitum monitoring}

$18 \mathrm{~h}$ procedure, $\min$

$695 \pm 99^{13}$

$635 \pm 82^{13}$

$747 \pm 82^{13}$

$32 \mathrm{~h}$ bed rest procedure,

$646^{19}$

$892^{19}$

first $24 \mathrm{~h}$

MSL: mean sleep latency; PLMS: periodic leg movements during sleep; SOREM: sleep onset in REM period 
Table 5. Drugs used in idiopathic hypersomnia

\begin{tabular}{|c|c|c|c|c|}
\hline Reference & $\begin{array}{l}\text { Patients } \\
\text { No }\end{array}$ & Type of trial & Benefit & $\begin{array}{l}\text { Level of } \\
\text { evidence }\end{array}$ \\
\hline \multicolumn{5}{|l|}{ Modafinil } \\
\hline 60 & 18 & $\begin{array}{l}\text { Observational } \\
\text { open }\end{array}$ & Less frequent daily naps in $89 \%$ & III \\
\hline 11 & 39 & $\begin{array}{l}\text { Observational } \\
\text { open }\end{array}$ & $\begin{array}{l}\text { ESS reduction }>4 \text { in } 62 \% \\
\text { Mean ESS reduction: }-6 \pm 5.4\end{array}$ & III \\
\hline 47 & 25 & $\begin{array}{l}\text { Observational } \\
\text { open }\end{array}$ & $\begin{array}{l}72 \% \text { have a complete }(\mathrm{ESS} \text { reduction }=-9) \text {, } \\
\text { and } 16 \% \text { a partial response to modafinil }\end{array}$ & III \\
\hline 7 & 104 & $\begin{array}{l}\text { Observational, } \\
\text { open, compared } \\
\text { to narcolepsy } \\
\text { type } 1\end{array}$ & $\begin{array}{l}\text { Over a period of } 4.7 \text { y long, mean ESS } \\
\text { reduction : }-2.6 \pm 5.1 \text { in IH, vs. }-3 \pm 5.1 \text { in the } \\
\text { narcolepsy group (ITT analysis). Mean } \\
\text { efficacy on analogic visual scale: } 6.9 / 10 \text { in } \mathrm{IH} \text {, } \\
\text { vs } 6.5 / 10 \text { in the narcolepsy group }\end{array}$ & $\mathrm{IIb}$ \\
\hline 49 & 14 & $\begin{array}{l}\text { Randomized, } \\
\text { double-blind } \\
\text { crossover, vs. } \\
\text { placebo }\end{array}$ & $\begin{array}{l}\text { In a composite group of } \mathrm{IH} \text { and narcolepsy } \\
\text { patients, improved driving performance and } \\
\text { improved MWT (from } 19.7 \pm 9.2 \text { min under } \\
\text { placebo to } 30.8 \pm 9.8 \mathrm{~min} \text { ) }\end{array}$ & $\mathrm{Ib}$ \\
\hline 48 & 33 & $\begin{array}{l}\text { Randomized, } \\
\text { double-blind } \\
\text { parallel, vs. } \\
\text { placebo }\end{array}$ & $\begin{array}{l}\text { Over } 3 \text { weeks, mean ESS reduction : }-6 \text { with } \\
\text { modafinil } 200 \mathrm{mg} / \mathrm{d} \text {, vs. }-1.5 \text { with placebo; } \\
\text { CGI improved : }-1 \text { point; MWT: }+3 \text { min vs } 0 \\
\text { min but not significant }\end{array}$ & $\mathrm{Ib}$ \\
\hline \multicolumn{5}{|c|}{ Methylphenidate } \\
\hline 47 & 40 & $\begin{array}{l}\text { Observational } \\
\text { open }\end{array}$ & $\begin{array}{l}52 \% \text { have a complete }(\text { ESS reduction }=-9) \text {, } \\
\text { and } 33 \% \text { a partial response to modafinil }\end{array}$ & III \\
\hline
\end{tabular}

Amphetamine, dextroamphetamine, metamphetamine

\begin{tabular}{|c|c|c|c|}
\hline 11 & 11 & $\begin{array}{l}\text { Observational } \\
\text { open }\end{array}$ & $54 \%$ are responders $(\mathrm{ESS}$ reduction $>4)$ \\
\hline 47 & 20 & $\begin{array}{l}\text { Observational } \\
\text { open }\end{array}$ & $\begin{array}{l}25 \% \text { are complete }(\text { ESS reduction }=-9) \text { and } \\
10 \% \text { partial responders }\end{array}$ \\
\hline \multicolumn{4}{|c|}{ Pemoline } \\
\hline 47 & 7 & $\begin{array}{l}\text { Observational } \\
\text { open }\end{array}$ & $43 \%$ are responders \\
\hline \multicolumn{4}{|c|}{ Mazindol } \\
\hline 9 & 37 & $\begin{array}{l}\text { Observational } \\
\text { open }\end{array}$ & $\begin{array}{l}\text { The mean ESS reduction was }-4.8 \pm 4.7 \text {; } \\
84 \% \text { of patients were responders }\end{array}$ \\
\hline \multicolumn{4}{|c|}{ Sodium oxybate } \\
\hline 61 & 46 & $\begin{array}{l}\text { Observational } \\
\text { open, compared } \\
\text { to narcolepsy }\end{array}$ & $\begin{array}{l}\text { The ESS reduction was }-3.5 \pm 4.5 \text {, similar to } \\
\text { its effect in narcolepsy type } 1(-3.2 \pm 4.2) \text {. } \\
\text { Sleep drunkenness was improved in } 71 \% \text { these }\end{array}$ \\
\hline
\end{tabular}


patients

\section{Pitolisant}

51

65

Observational

$36 \%$ of patients were responders (ESS

III

open

reduction $>3$ )

\section{Flumazenil}

52

36

Observational

$68 \%$ of patients were responders (mean ESS

III

open

reduction $=5$ )

\section{Clarithromycin}

53

53

Observational

$34 \%$ of patients chose to use it in the long term

III

open

62

23, with Randomized,

$10 \mathrm{IH}$ double-blind

ESS reduction $=-3.9$ between clarithromycin

II crossover, vs. placebo long sleep time; Improved QoL. Unchanged PVT

CGI : Clinical general impression ; ESS: Epworth sleepiness score; ITT : intention to treat. MWT : maintenance of wakefulness test; PVT: psychomotor vigilance test; QoL: quality of life. 


\section{Legend of the figures}

Figure 1- The various prolonged monitoring procedures used to diagnose idiopathic hypersomnia, when the multiple sleep latency is normal or borderline.

Figure 2 - Hypnogram in a patient with idiopathic hypersomnia (lower panel), measured during prolonged monitoring (here $18 \mathrm{~h}$ long) in Paris (France), compared to a healthy subject (upper panel). Sleep is highly efficient, 9 sleep cycles are performed instead of 4, and slow wave sleep is present even during morning sleep.

Figure 3 - Decreased regional blood flow in idiopathic hypersomnia (compared to healthy controls, left panel) during brain scintigraphy performed in awake subjects correlates with the level of sleepiness measured by Epworth sleepiness scale (right panel, top) and by multiple sleep latency test (right panel, down). (From Boucetta S, Montplaisir J, Zadra A, et al. Altered Regional Cerebral Blood Flow in Idiopathic Hypersomnia. Sleep. 2017;40(10); with permission.) 


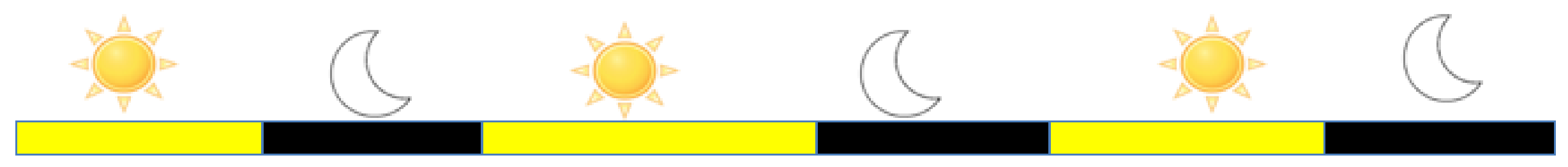

\section{Paris}
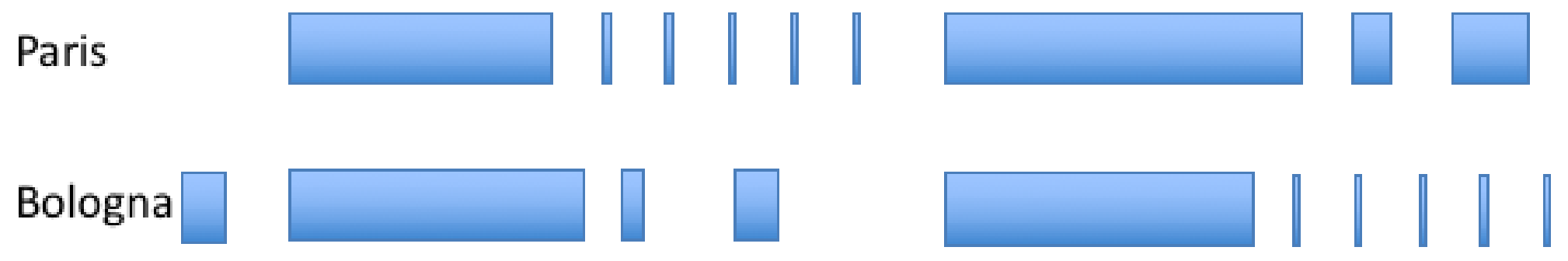

Montpellier
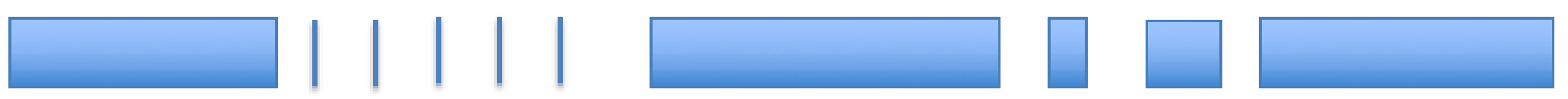


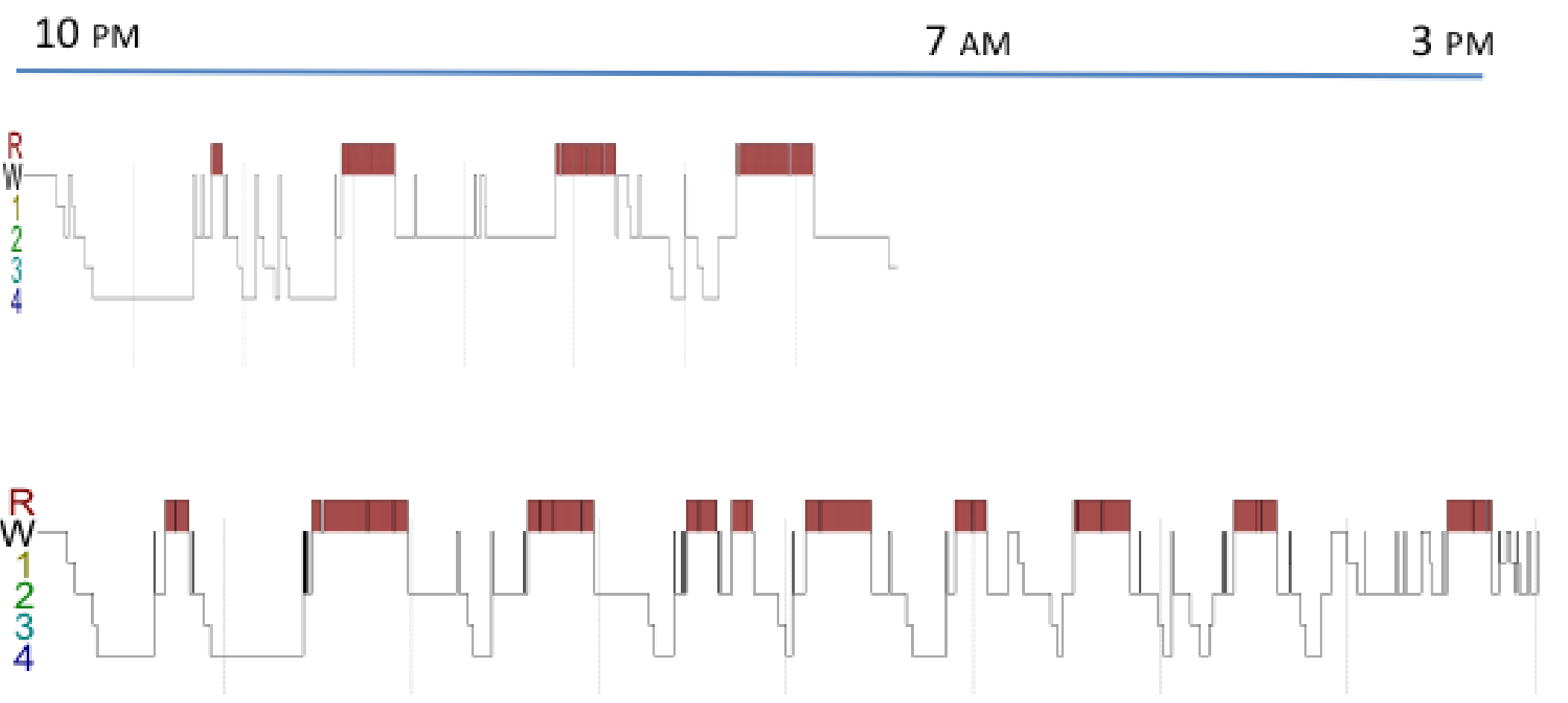



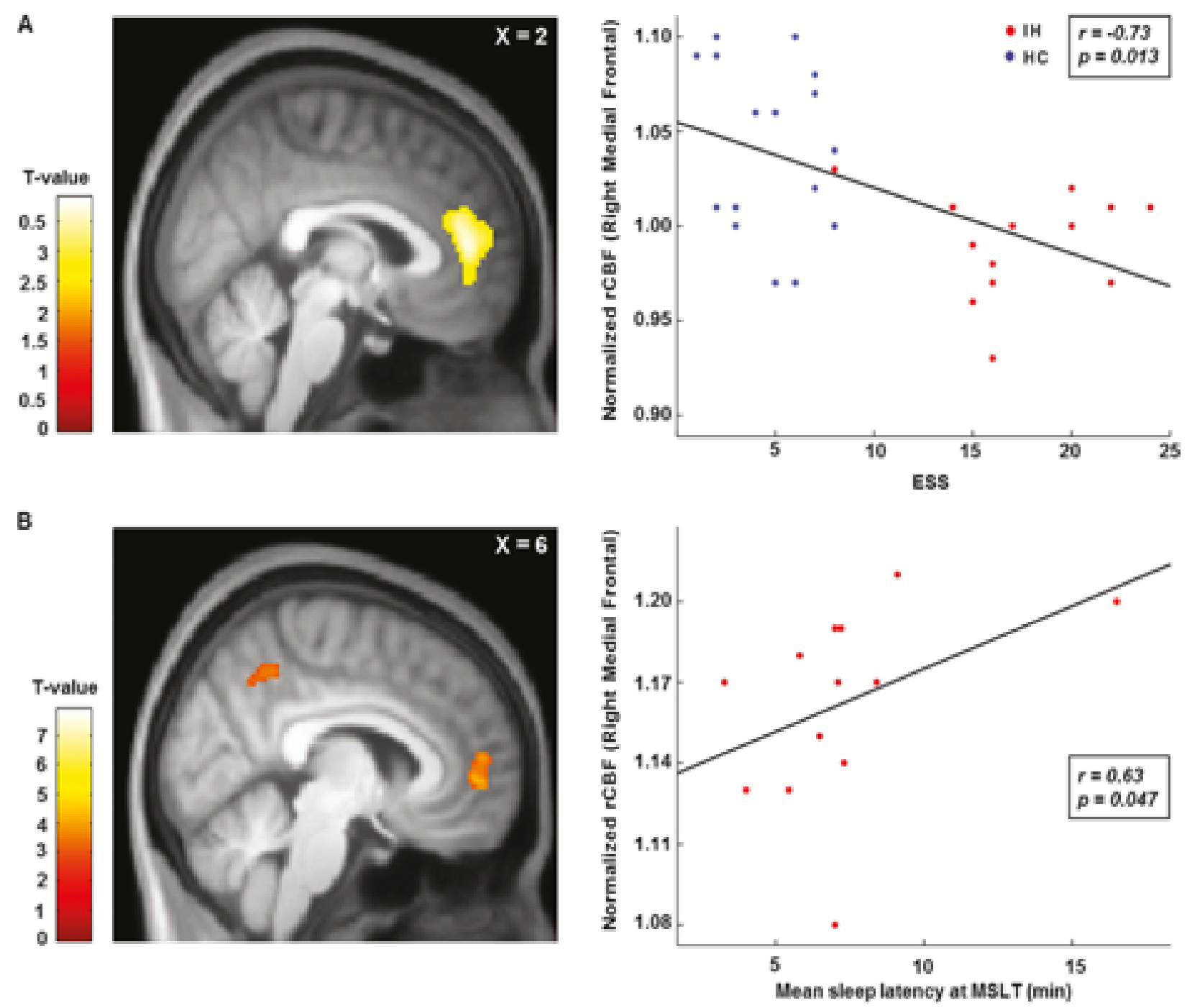